\title{
Laurin-Sandrow syndrome (mirror hands and feet and nasal defects): description of a new case
}

\author{
M L Martinez-Frias, M Alcaraz, P Espejo, M A Gómez, R García de León, \\ L González Moro
}

\begin{abstract}
A child with complete syndactyly of cup shaped hands and mirror polysyndactyly of the feet, together with a nasal defect, was identified out of a total of 1031439 livebirths. She had a pattern of multiple congenital anomalies which was similar to that first described by Laurin et al in 1964 and by Sandrow et al in 1970. Two more cases with a similar pattern of congenital anomalies have recently been published so this is the fifth reported case with this constellation.
\end{abstract}

( $($ Med Genet 1994;31:410-412)

ECEMC Coordinating

Group and

Departamento de

Farmacología,

Facultad de Medicina,

Universidad

Complutense, 28040

Madrid, Spain

M L Martínez-Frias

ECEMC Peripheric

Group and Servicio de

Pediatría, Hospital

Virgen del Castillo de

Yecla, Murcia, Spain

M Alcaraz

P Espejo

M A Gómez

R Garcia de León

L González Moro

Correspondence to Dr Martinez-Frias.

Received 7 October 1993 Revised version accepted for publication 14 December publicat

In 1964, Laurin et al ${ }^{1}$ described a boy who had complete polysyndactyly of his hands which were held in a "semicupped position" and had "perfect mirror feet". He also had bilateral absence of the radius and tibia with bilateral reduplication of the ulna and fibula. Sandrow et $a l^{2}$ in 1970 described a girl who had mirror polysyndactyly of both hands and feet with duplication of the ulna, fibula (dimelia), and tarsal bones, together with nasal anomalies consisting of hypoplasia of the nasal alae with coloboma and short columella. Her father was also affected, but to a different degree. These last authors considered that the case reported by Laurin $e t$ al" was "almost identical" to their two cases.

Recently, two more cases have been pubthat described by Laurin et $a l^{1}$ and Sandrow et $a .^{2}$ lished ${ }^{34}$ with a pattern of anomalies similar to

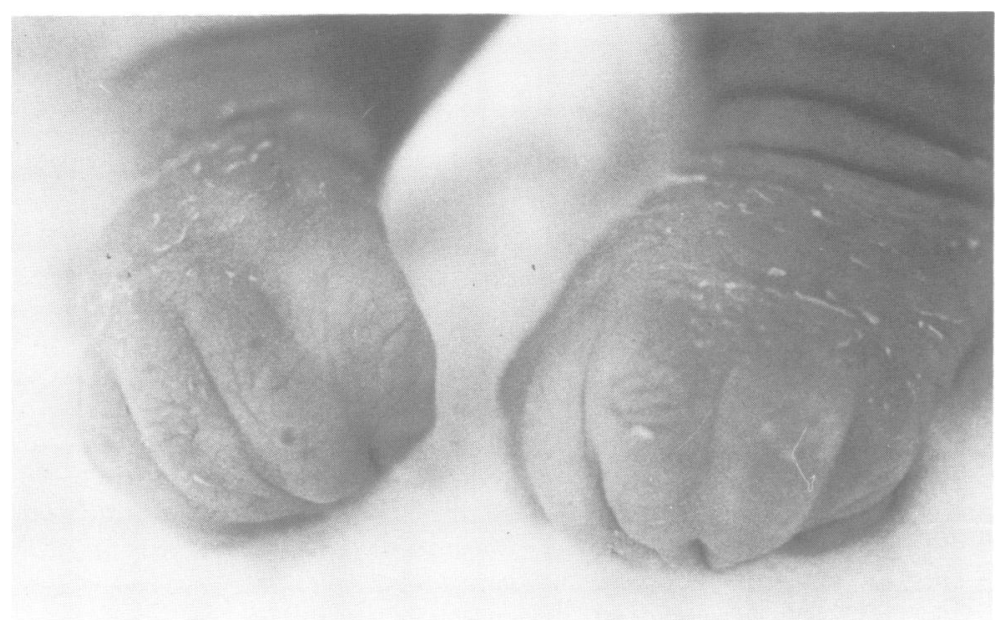

Figure 1 Appearance of hands: note complete cup shaped bilateral syndactyly.
Here we present a girl with mirror polysyndactyly of the feet, complete cup shaped syndactyly of the hands, and nasal defects. This infant was identified from the 1031439 livebirths registered by the Spanish Collaborative Study of Congenital Malformations (ECEMC)

\section{Case report}

The child was born to a G2, P2, 30 year old mother and 39 year old father. The parents were healthy and non-consanguineous. The pregnancy was only complicated by mild vaginal bleeding for one day in the third month. A girl who weighed $3250 \mathrm{~g}$ (75th to 97th centile) was spontaneously delivered at 40 weeks of gestation. Her length was $47 \mathrm{~cm}$ (10th to 25 th centile) and OFC was $34 \mathrm{~cm}$ (50th to 75 th centile). Physical examination at birth showed: complete bilateral syndactyly of all fingers, forming a rosebud type of configuration (figs 1 and 2) and mirror polysyndactyly of the feet with a completely fused central hallux (fig 3 ). She also had a peculiar nose with hypoplastic nasal alae and a very short columella (fig 4). Radiological examination showed (fig 5) five metacarpals with five broad proximal phalanges and distally fused fingers, with normal radii and ulnae. Radiologists considered that the length of the long bones in the lower limbs fell within the normal range (fig 6). The karyotype was normal $(46, \mathrm{XX})$.

\section{Discussion}

The pattern of anomalies observed in the case we present here, though similar to that observed in the previously described cases, ${ }^{1-4}$

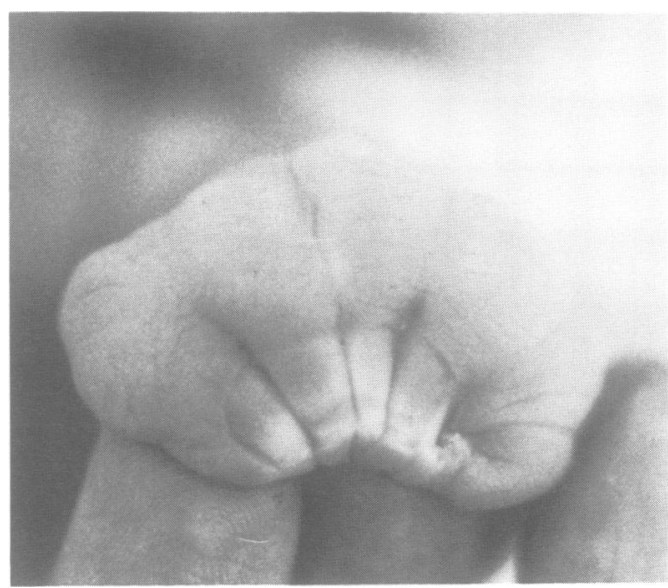

Figure 2 Syndactyly of all fingers in a rosebud type of configuration. 


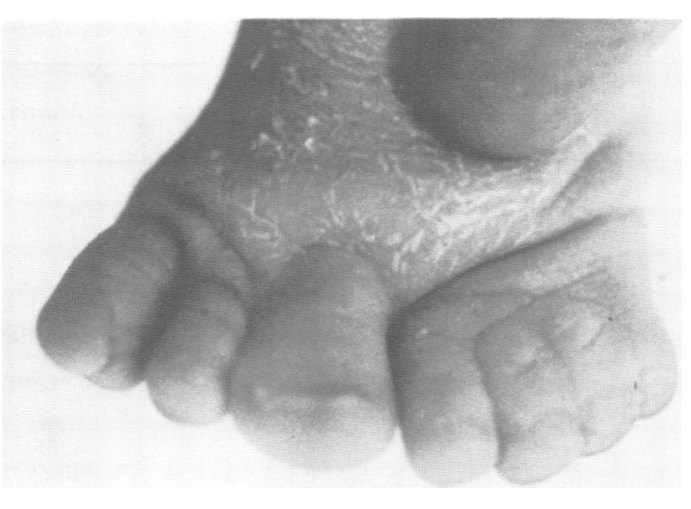

Figure 3 Appearance of feet: mirror polydactyly with completely fused central hallux.

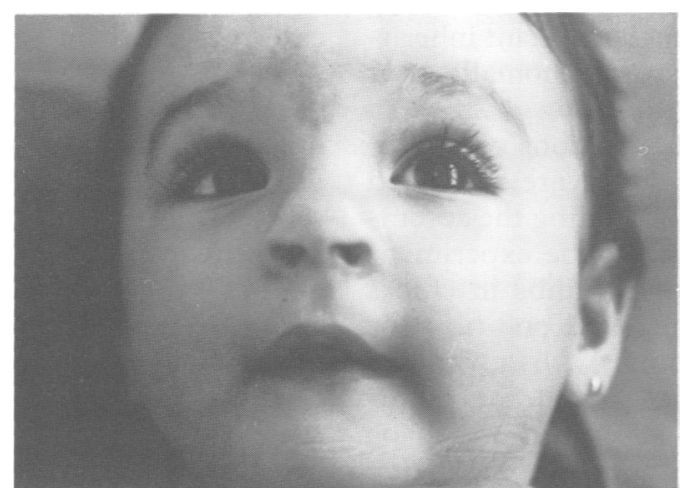

Figure 4 Facial appearance at 9 months of age. Note the peculiar nose with a very short columella.

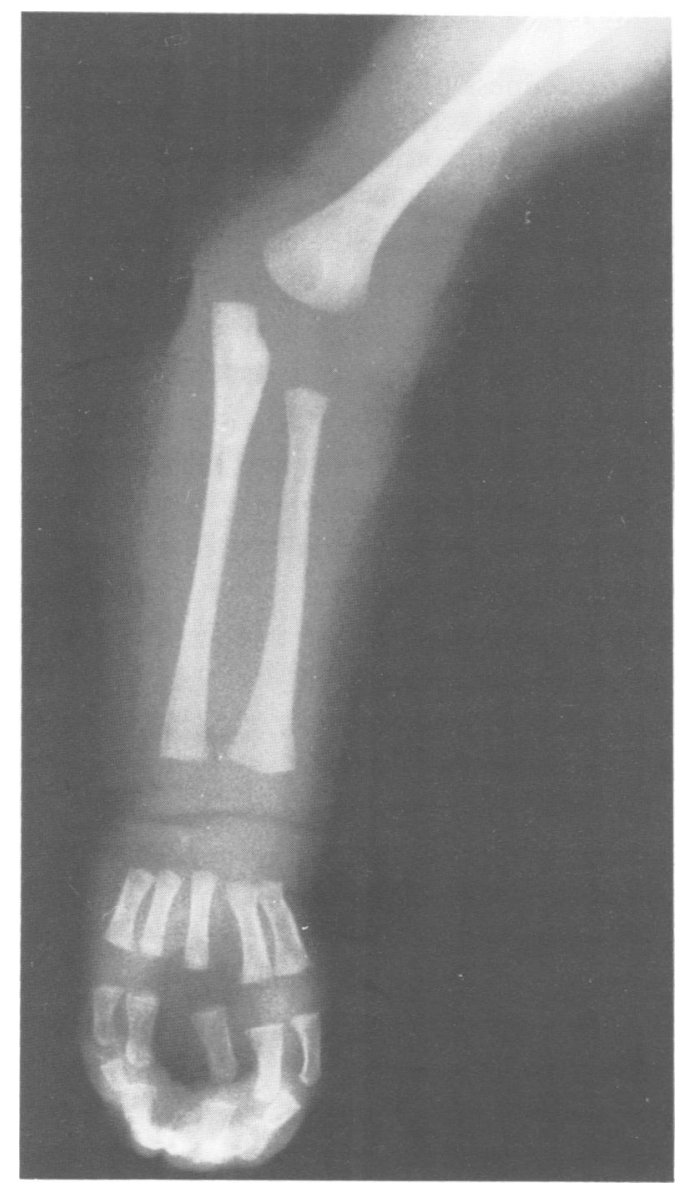

Figure 5 Radiograph of upper limbs. Normal radii and ulnae with five metacarpals and five broad first phalanges distally fused.

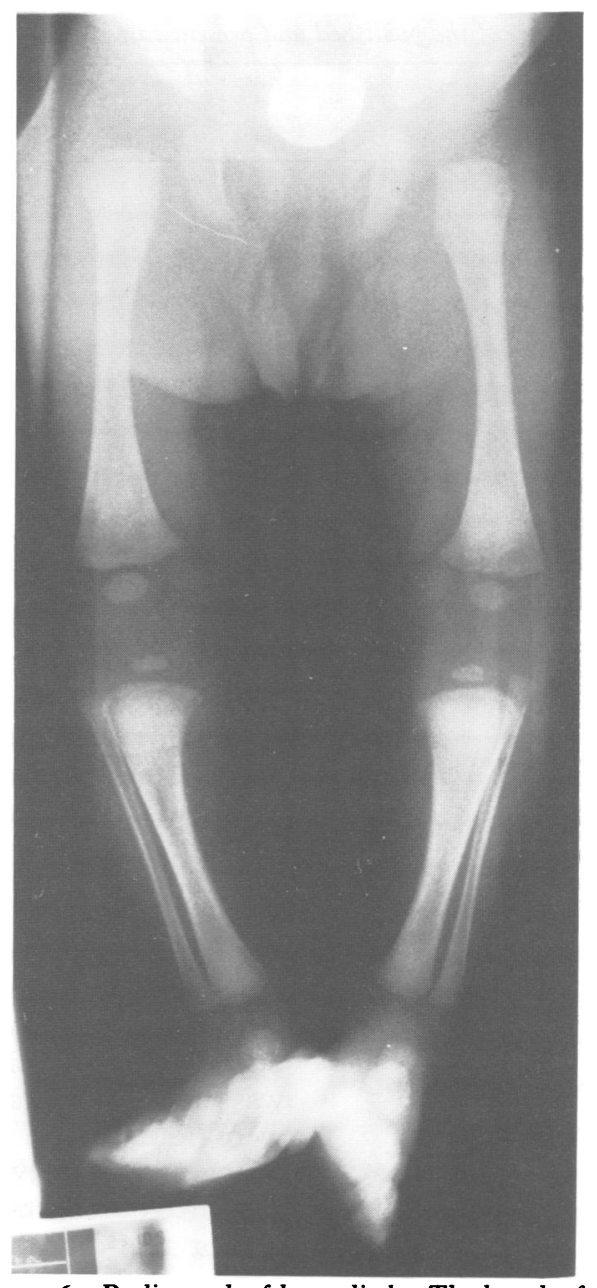

Figure 6 Radiograph of lower limbs. The length of the long bones is within the normal range.

shows a new degree of variability, since the child had complete syndactyly of both hands leading to a rosebud appearance, but did not have supernumerary metacarpal bones. She did, however, have five proximal phalanges. The infant had normal upper and lower long bones and the mirror feet with fused midline hallux did not show equinovarus deformity.

The variability in the expression of the congenital anomalies observed in the published cases (table) was also observed in the father and the daughter described by Sandrow et $a l^{2}$ and Martin et al. ${ }^{4}$ However, the latter authors, based on the absence of dimelia and the presence of tibial hypoplasia, together with a nasal defect consisting of a "deep vertical groove running the entire length of a very short columella", concluded that their case was a separate entity from the one described by Sandrow et al..$^{2}$ Kogekar $e t a l^{3}$ considered their case to be the same entity as described by Sandrow et al, ${ }^{2}$ although neither fibulae nor ulnae were duplicated in their child either.

Complete syndactyly of the hand with a cup shaped appearance was described in 1940 by Haas $^{5}$ in a brother and sister, who did not have other congenital defects. More recently, Rambaud-Cousson et $a l^{6}$ reported a case who presented with polysyndactyly of all six fingers giving the hands a cup shaped appearance (Haas type). The infant also had six well formed and unfused toes on both feet, with 


\begin{tabular}{|c|c|c|c|c|c|}
\hline Description & $\begin{array}{l}\text { Laurin } \\
\text { et } \text { al }^{1}\end{array}$ & $\begin{array}{l}\text { Sandrow } \\
\text { et } a l^{2}\end{array}$ & $\begin{array}{l}\text { Kogekar } \\
\text { et al }\end{array}$ & $\begin{array}{l}\text { Martin } \\
\text { et } a l^{4}\end{array}$ & $\begin{array}{l}\text { Present } \\
\text { case } \\
(E C E M C \text { case ) }\end{array}$ \\
\hline \multicolumn{5}{|l|}{ Cup shaped hands with } & \\
\hline Mirror hands polydactyly & + & + & + & + & $-1+?$ \\
\hline Mirror feet polysyndactyly & + & + & + & + & + \\
\hline Equinovarus feet & + & + & + & + & - \\
\hline Nasal anomalies & $+1-?$ & + & + & + & + \\
\hline Shortness of tibiae & - & - & + & + (Right) & - \\
\hline Shortness of fibulae & - & - & + & - & - \\
\hline Duplication of ulna & + & + & - & - & - \\
\hline Duplication of fibulae & + & + & - & - & - \\
\hline Chromosomes/sex & ?/boy & $? /$ girl & $\mathrm{XY} /$ boy & ?/girl & $\mathrm{XX} /$ girl \\
\hline Birth weight (g) & & $?$ & & 4205 & 3250 \\
\hline Gestational age (wk) & $?$ & $?$ & ? & 40 & 40 \\
\hline Maternal age & $?$ & $?$ & $?$ & 33 & 30 \\
\hline Paternal age & & & & & \\
\hline Other affected relatives & None & Father & None & Father & None \\
\hline
\end{tabular}

unilateral absence of the tibia. The family history suggested autosomal dominant inheritance. However, neither nasal anomalies nor mirror feet were present.

These mirror image duplications of the digits are similar to those that are produced experimentally in chicks, including the accompanying anomalies. ${ }^{78}$ In fact, the experimentally produced mirror image limbs in chicks included duplicated fibulae and one tibia, or frequently a solitary fibula, with a variable degree of expressivity. Although the femur was never duplicated, changes of its shape were found with or without accompanying changes in the pelvis. Thus, it appears that the presence of long bone anomalies in cases with mirror feet polydactyly which is related to abnormal development could reflect different degrees of severity.

The different degrees of affectedness of the long bones in the five patients described (table), as well as the overlapping of the other anomalies, suggest that clearly distinct groups cannot be established. However, the nose anomalies, which appear to be different in the different reported cases, have as a common finding (at least in four of the five cases) a defective columella which was always very short. This defect may be related to the abnormal developmental mechanism and would lead to different types of clinical appearance. In the first published case, ${ }^{1}$ the authors only described the orthopaedic defects and did not mention any facial characteristics. However, looking at the photographs of the child when he was 6 years old, ${ }^{1}$ it does not seem unlikely that he could also have had some degree of nasal anomalies.

The clinical variability detected in the published cases has also been observed within the same family, ${ }^{24}$ in which the severity of the limb defects as well as the nose anomalies differed in degree. Thus, it could be considered that the case published by Kogekar et $a l,{ }^{3}$ the family presented by Martin et $a l^{4}{ }^{4}$ and the case we describe here have the same condition as the one described by Laurin et $a l^{1}$ and Sandrow et $a l .^{2}$ At least, there is not enough information to support the assumption that these cases are different conditions. We suggest that this entity be called Laurin-Sandrow syndrome.

Sandrow et $a l^{2}$ postulated autosomal or $\mathrm{X}$ linked dominant inheritance, and Martin et al concluded that autosomal dominant inheritance was the most likely mode of transmission in their family. The case presented by Kogekar et $a l^{3}$ was sporadic and they also considered that it could represent a new mutation, although they did not exclude autosomal recessive inheritance. Our case, also sporadic, was born to a 39 year old father, supporting the assumption of a very infrequent autosomal dominant new mutation.

This work was supported in part by a grant from Direccion General de Salud Pública (Ministerio de Sanidad y Consumo) Spain and by Fundación ONCE, Spain.

1 Laurin CA, Favreau JC, Labelle P. Bilateral absence of the radius and tibia with bilateral reduplication of the ulna and fibula. A case report. $f$ Bone foint Surg (Am) and fibula. A

2 Sandrow $R$, Sullivan $P$, Steel $H$. Hereditary ulnar and fibular dimelia with peculiar facies - a case report. $\mathcal{F}$ Bone foint Surg $(A m)$ 1970;52:367-70

3 Kogekar N, Teebi AS, Vockley J. Sandrow syndrome of mirror hands and feet and facial abnormalities. $A m \mathcal{f} M e d$ Genet 1993; 46:126-8.

4 Martin RA, Jones MC, Jones KJ. Mirror hands and feet with distinct nasal defect, an autosomal dominant condition. a distinct nasal defect, an autosom

5 Haas SL. Bilateral complete syndactylism of all fingers. $A m \mathcal{F}$ Surg 1940;50:365-6.

6 Rambaud-Cousson A, Anwar AD, Ahmad SZ, Amin T Syndactyly type IV/hexadactyly of feet associated with unilateral absence of the tibia. Am $f$ Med Genet 1991;40:144-5

7 Tickle C, Lee J, Eichele G. A quantitative analysis of the effect of all-trans-retinoic acid on the pattern of chick wing development. Dev Biol 1985;109:82-95.

8 Wilde SM, Wedden SE, Tickle C. Retinoids reprogramme preband mesenchyme to give changes in limb pattern. Development 1987;100:723-33. 